\title{
A 60-Second Microwave-Assisted Synthesis of Nickel Foam and Its Application to the Impregnation of Porous Scaffolds
}

\author{
Enrique Ruiz-Trejo, ${ }^{*, z}$ Abul K. Azad, and John T. S. Irvine, \\ School of Chemistry, University of St Andrews, St Andrews, Fife KY16 9ST, United Kingdom
}

\begin{abstract}
A rapid and facile method to prepare nickel foam from nickel nitrate and glycine using a conventional microwave oven is presented. The foam, characterized by SEM, XRD-Rietveld, TG, magnetization measurements and BET contains mostly nickel metal ( $80 \mathrm{w} \%)$ and nickel oxide ( $20 \mathrm{w} \%)$; it exhibits pores in the sub micrometric and nanometric scale and consists of particles with an average diameter of $45-47 \mathrm{~nm}$ and BET surface of $15.9 \mathrm{gm}^{-2}$. This microwave-assisted combustion synthesis is used to infiltrate porous ceramic scaffolds with nickel metal as a potential method to accelerate the fabrication of electrodes in solid oxide fuel cells and electrolysers. After repeated impregnation, the scaffolds of $\mathrm{Ce}_{0.9} \mathrm{Gd}_{0.1} \mathrm{O}_{2}$, saffil (high temperature insulating brick), $\mathrm{La}_{0.2} \mathrm{Sr}_{0.7} \mathrm{TiO}_{3}$ and $\mathrm{BaCe}_{0.5} \mathrm{Zr}_{0.3} \mathrm{Y}_{0.16} \mathrm{Zn}_{0.04} \mathrm{O}_{3-\delta}$ were black, exhibited electrical continuity and were easily lifted with a magnet. A comparative SEM study of the microstructure of the porous scaffolds with and without nickel is presented.

(C) The Author(s) 2014. Published by ECS. This is an open access article distributed under the terms of the Creative Commons Attribution Non-Commercial No Derivatives 4.0 License (CC BY-NC-ND, http://creativecommons.org/licenses/by-nc-nd/4.0/), which permits non-commercial reuse, distribution, and reproduction in any medium, provided the original work is not changed in any way and is properly cited. For permission for commercial reuse, please email: oa@electrochem.org. [DOI: 10.1149/2.0531503jes] All rights reserved.
\end{abstract}

Manuscript submitted September 24, 2014; revised manuscript received December 15, 2014. Published December 30, 2014.

Nickel cermets are the state of the art material as electrodes for Solid Oxide Fuel Cells and Solid Oxide Electrolysers. A typical anode configuration consists of a composite of nickel metal and the corresponding electrolyte such as a stabilized zirconia, a doped ceria or a mixed barium cerate-zirconate. ${ }^{1-3}$ A common fabrication method involves mixing thoroughly $\mathrm{NiO}$ and the zirconia, suspension in a slurry, application by tape casting or screen printing, co-firing with other components -electrolyte, support, etc. - and finally reduction insitu of the $\mathrm{NiO}$ to $\mathrm{Ni}$. Alternatively, the composites can be fabricated by preparing first a porous scaffold of the electrolyte and infiltrating it with a solution of the nickel nitrate; this is then decomposed to the oxide by heating and the cycle of infiltration and decomposition is repeated until the desired loading and microstructure is obtained. This method provides a useful way of controlling the microstructure ${ }^{4}$ and the loading and produces excellent results in terms of electrochemical performance, ${ }^{3,5}$ it is, however energy consuming since the whole cell (scaffold, electrolyte, etc.) has to be heated and cooled repeatedly; it is time consuming as this long process has to be repeated several times.

In the work presented here, we show the potential of microwaves to accelerate the process of impregnation in a porous scaffold. The synthesis of metallic nickel by combustion synthesis has been reported to take place in a hot-plate ${ }^{6}$ and an insight into the reaction mechanism has been given before. ${ }^{7}$ Previous reports indicate the production of nickel metal by irradiating with microwaves a mixture of nickel nitrate and an organic fuel ${ }^{8-10}$ with reaction times up to 10 minutes. Here, we take the experiments further by simplifying and speeding up the synthesis and using it as a processing technique with great potential to produce anodes for fuel cells. First we confirm that nickel metal can be obtained by direct action of microwaves from a conventional oven and a suitable solution of nickel nitrate and glycine. Secondly, we use the method to deposit nickel metal directly in a variety of porous structures and characterize them by electron microscopy.

\section{Experimental}

The desired amount of glycine was dissolved in a $2 \mathrm{M}$ water-based solution of $\mathrm{Ni}\left(\mathrm{NO}_{3}\right)_{2}$. In a typical experiment $0.4 \mathrm{ml}$ of solution were placed in an open vial glass and irradiated in a microwave oven at maximum power $(1000 \mathrm{~W})$ for $60 \mathrm{~s}$. The oven used was a Sanyo Microwave Oven Super shower wave $1000 \mathrm{~W}$ working at $2.45 \mathrm{GHz}$.

*Electrochemical Society Active Member.

${ }^{\text {z}}$ E-mail: enrique.ruiz-trejo@imperial.ac.uk; jtsi@st-andrews.ac.uk
The samples used for analysis were a mixture of the different reaction batches. In this way, we comply with local health and safety regulations while averaging over dozens of reaction batches.

The microstructure was studied with a JEOL 5600 scanning electron microscope (SEM). High magnification images were obtained with a Field Emission SEM JEOL JSM-6700F. The distribution of the deposited metals in the porous structure was studied by EDX elemental analysis.

Crystal structure and phase purity were examined by X-ray diffraction (XRD) analysis of powders in an EMPYREAN diffractometer system in reflection mode. Incident radiation was generated using a $\mathrm{Cu}-\mathrm{K}_{\alpha 1}$ source $(\lambda=1.54056 \AA)$. The step scan covered a 2 theta range from 10 to $90 \mathrm{deg}$ with a step-size of $0.017 \mathrm{deg}$ and a collection time $1 \mathrm{~s}$ per step. Diffraction data sets were refined by the Rietveld method using the FullProf software. ${ }^{11}$ Diffraction peakshapes were quantified using a pseudo-Voigt function, with a peak asymmetry correction applied at angles below $55 \mathrm{deg}$ in 2 theta. Background intensities were described by a Chebyshev polynomial with six coefficients.

A few milligrams of the samples were analyzed by thermogravimetry using a Netzsch TASC 414/3 equipment. The heating rate was $5 \mathrm{Kmin}^{-1}$ in air. The BET surface area was measured with a Micromeritics TriStar II equipment. For all samples the electrical continuity was tested with a 2 point hand-held ohmmeter and in a selected case the conductivity was measured in $10 \%$ wet $\mathrm{H}_{2}$ using a 4-point $\mathrm{dc}$ technique. Silver electrodes were painted on the sample and silver wire was used to connect to the measuring equipment (Autolab PGSTAT 302). To ensure full reduction and equilibrium the sample was kept at $650^{\circ} \mathrm{C}$ for 2 hours before measuring while cooling down stopping 1 hour at each measured temperature. DC magnetic measurements were performed in a Quantum Design MPMS-XL Superconducting Quantum Interference Device (SQUID) magnetometer. Magnetization versus magnetic field measurements were performed at room temperature between 0 and $22 \mathrm{kOe}$.

Four types of porous scaffolds were tested: $\mathrm{La}_{0.2} \mathrm{Sr}_{0.7} \mathrm{TiO}_{3}$ (LST) $40 \%$ porosity, $\mathrm{Ce}_{0.9} \mathrm{Gd}_{0.1} \mathrm{O}_{2} \quad$ (CGO) $50 \%$ porosity, $\mathrm{BaCe}_{0.5} \mathrm{Zr}_{0.3} \mathrm{Y}_{0.16} \mathrm{Zn}_{0.04} \mathrm{O}_{3-\delta}$ (BCZYZ) 50\% porosity and high temperature insulating brick (Saffil) $80-90 \%$ porosity. Except Saffil, all of them are commonly used in anode composites. The approximate dimensions were LST: $1 \times 2 \times 2 \mathrm{~mm}$, CGO $1 \times 2 \times 4 \mathrm{~mm}$, Saffil $5 \times 5 \times 5 \mathrm{~mm}$ and BCZYZ $2 \times 2 \times 5 \mathrm{~mm}$. These backbones were infiltrated with a solution of nickel nitrate and glycine (One mol of nitrate per $3 \mathrm{~mol}$ of glycine) and then irradiated in the microwave oven for $60 \mathrm{~s}$. The process was repeated several times to increase the nickel loading. In some cases the infiltration was assisted by placing the samples and the solution under vacuum. 


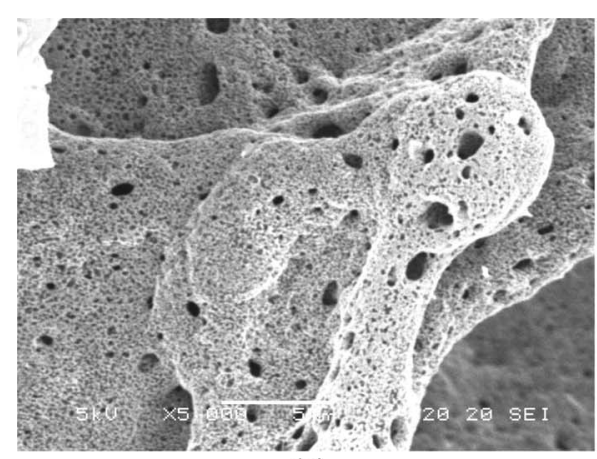

(a)

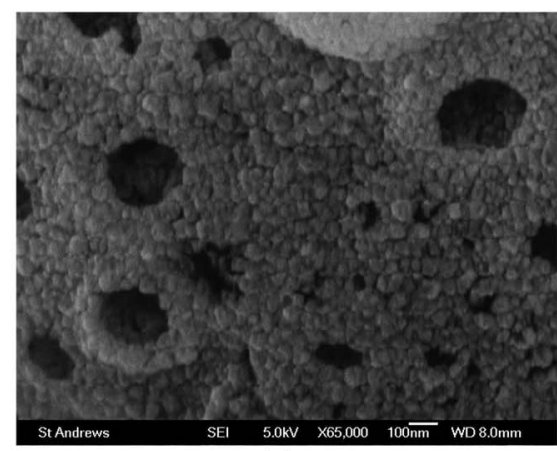

(c)

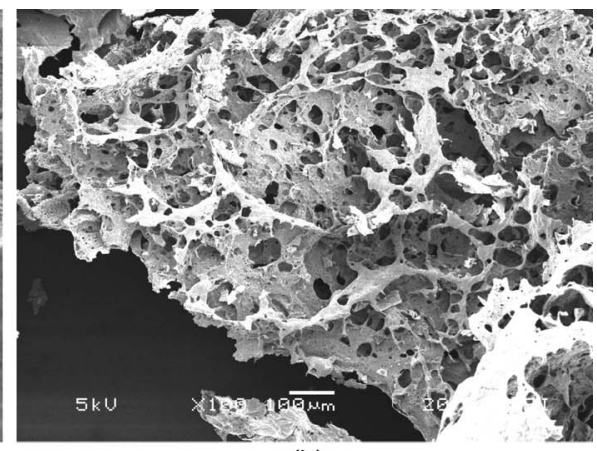

(b)
Figure 1. a) Micrograph of the structure of the foam. Magnification $\times 100$. b) Magnification $\times 5000, c)$ Magnification $\times 65000$.

\section{Results}

Synthesis. - Several ratios of glycine/nitrate were tested ranging from the lean to the rich fuel. The optimum ratio for a complete reaction was $3 \mathrm{~mol}$ of glycine per mol of nitrate and the completion time of the reaction was $60 \mathrm{~s}$. For quantities smaller than $0.5 \mathrm{ml}$ the solution boiled and evaporated in the first 15 seconds of irradiation, followed by the formation of foam, evolution of gases and a very exothermic reaction with flames. In the last 15 seconds there was vigorous sparking. In some cases there was a final glow of some areas of the material. The residues were mainly foam mixed with black powders. Four quick tests proved the unequivocal presence of nickel metal: a) the aforementioned bright sparks quite distinct of a metal-microwave interaction b) small lumps of material with a typical white metallic lustre were observed in the vial c) the black powder and the metal lumps were easily attracted by a magnet unlike what is expected from $\mathrm{NiO}$. d) A test of electrical continuity with an ohmmeter confirmed the presence of metallic nickel.

For comparison, the same initial solution was heated in a hot plate but no spontaneous combustion took place. No traces of metallic nickel were detected after the decomposition by any of the tests used above. It has been reported before that it is possible to obtain nickel metal using a hot plate but the stoichiometric ratios were different in those reports. ${ }^{6,7}$

Figure 1a-1c displays the microstructure of the foam at different magnifications. Figure 1a shows large pores in the sub millimetric range, Figure $1 \mathrm{~b}$ displays a higher magnification with sub-micrometric pores; the constituting particles are not yet visible. Finally, Figure 1c proves that the foam is constituted by nanoparticles with a relative narrow size distribution; the particles, with an average of ca $45-47 \mathrm{~nm}$, were agglomerated.

Figure 2 displays the XRD-Rietveld plot showing a predominance of $\mathrm{Ni}$ metal (fcc) as the main component with $\mathrm{NiO}$ as the secondary phase. The broadening and asymmetry of the peaks was attributed to the nanometric nature of the sample. The estimated nickel metal content in was $80 \mathrm{w} \%$ with $20 \mathrm{w} \%$ of nickel oxide.

The calculated cell parameters were $3.4841 \AA$ for Ni and $4.1275 \AA$ for $\mathrm{NiO}$; both values presented considerable compression compared to bulk theoretical values of $3.523 \AA$ and $4.1769 \AA$ respectively. The crystallite size estimated with the Scherrer formula (taking the shape factor as 0.89 for a sphere) was $46 \mathrm{~nm}$ for $\mathrm{Ni}$ and $27 \mathrm{~nm}$ for $\mathrm{NiO}$. Whereas the value of $\mathrm{Ni}$ seemed to correspond very well with the size of the nanoparticles seen in Figure 1c, the value for NiO crystallite seemed overestimated, was dependent upon the selected reflection and probably does not have a physical meaning. It can be reasonable assumed that the oxide was covering the particles of nickel; $\mathrm{Ni}$ and $\mathrm{NiO}$ could not be separated with a magnet indicating they were bonded somehow. The thickness of the oxide shell can be roughly estimated as follows: we considered the metallic nickel as spheres with diameter of $46 \mathrm{~nm}$; taken the density of $\mathrm{Ni}$ as $8.908 \mathrm{gcm}^{-3}$ and that of $\mathrm{NiO}$ as $6.67 \mathrm{gcm}^{-3}$, a simple geometrical estimation gave a thickness of $2.3 \mathrm{~nm}$ for the oxide shell around the Ni metal nanoparticles. With the volume and the mass of these metal nanoparticles coated with the oxide, we estimated the specific surface area to be ca. $14.2 \mathrm{~m}^{2} \mathrm{~g}^{-1}$. This rough calculation matches well with the measured BET surface of $15.9 \mathrm{~m}^{2} \mathrm{~g}^{-1}$.

A $\mathrm{NiO}$ shell of $2 \mathrm{~nm}$ around a nanoparticle of $46 \mathrm{~nm}$ diameter is likely to be strained and this could explain the large value of the cell parameter for $\mathrm{NiO}$. Incidentally, the process produces a very peculiar magnetic interface: that of a ferromagnetic metal and the antiferromagnetic oxide with a very limited magnetic domain.

Figure 3 shows the mass change of a few milligrams of foam upon heating in air. The main process is the oxidation of nickel metal to nickel oxide.

In principle, the total content of nickel metal could also be obtained by the difference in weight observed in Figure 3, yet the drift in the instrument impedes a precise determination as no unambiguous initial base-line can be defined. Nonetheless, no large amounts of carbon (i.e. this would be seen as a weight loss) seemed to be present in the foam.

The magnetization curve for the nickel foam gave a value of 44 $\mathrm{emug}^{-1}$ while the theoretical magnetization is $\sim 54.97 \mathrm{emug}^{-1}$ at room temperature. ${ }^{12}$ The calculated metallic nickel content is then $80 \mathrm{w} \%$ very much in accord with the XRD-Rietveld analysis.

Applications: accelerated impregnation.- We impregnated four porous scaffolds: CGO, LST, BCZYZ and saffil. The latter was very porous (80-90\%) and despite the softness it was capable of standing 


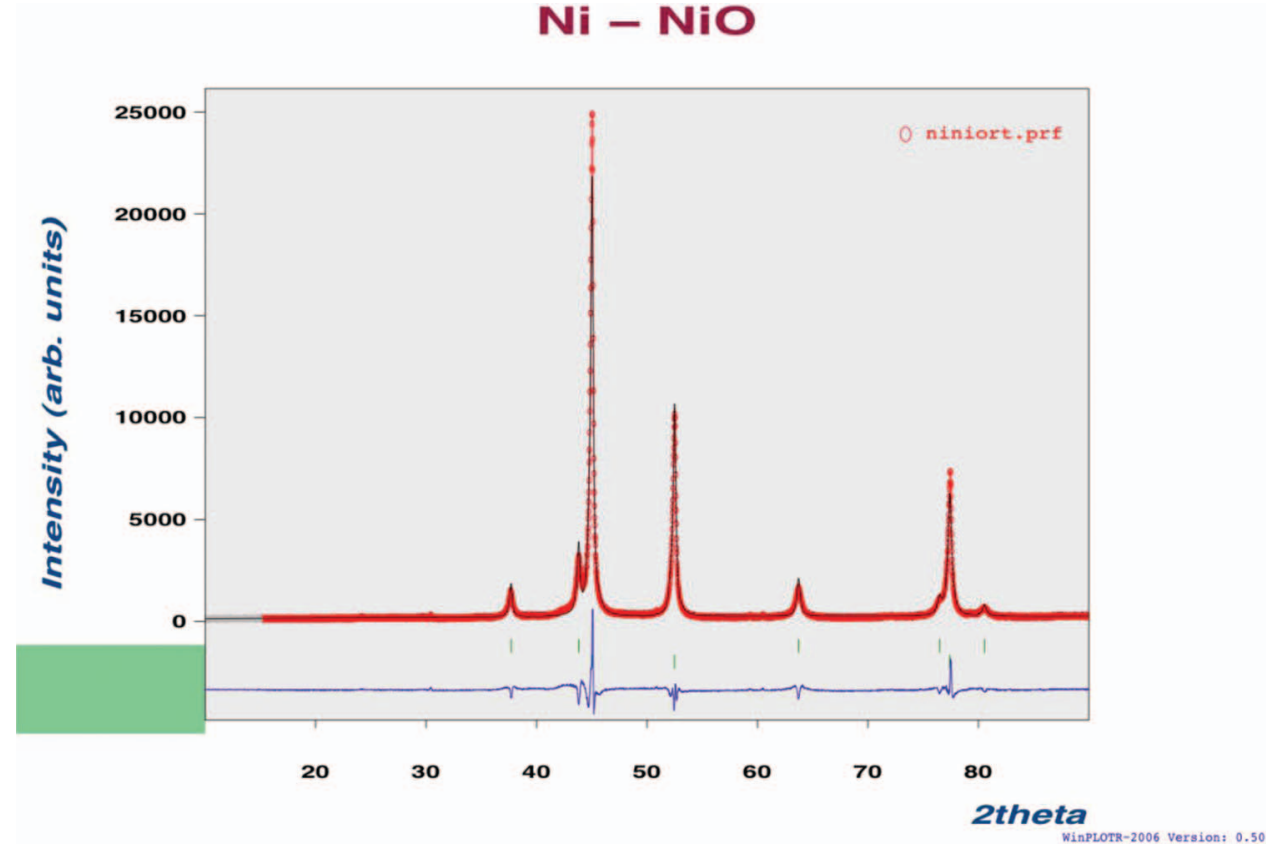

Figure 2. Rietveld plot of the product after $60 \mathrm{~s}$ of irradiation. Peaks at 44.4, 51.8 and $76.3 \mathrm{deg}$ correspond to Ni metal, the rest correspond to NiO.

the exothermic reaction of formation of nickel. The saffil block was infiltrated and irradiated in the microwave 5 times at $1000 \mathrm{~W}$ for $60 \mathrm{~s}$ each time; the final load was $60 \mathrm{w} \%$. There was no considerable damage to the structure of the saffil; excess nickel was removed from the surface of the material between impregnations. Figure 4 shows the microstructure of two cubes of saffil, with and without nickel. The piece impregnated with nickel was black, easily lifted with a magnet and exhibited electrical continuity as tested with a two-point ohmmeter.

The LST scaffold was mechanically robust, cream in color but less porous compared with the Saffil. Infiltration of the solution took longer times but was accelerated in vacuum. After 3 impregnations the material was black both in the surface and in the interior of the sample and reached a $2 \mathrm{w} \%$ loading. The metal loadings were smaller than in the case of the Saffil as the limited porosity retained less infiltrating solution. Further infiltration was not possible without mechanical damage to the scaffold.

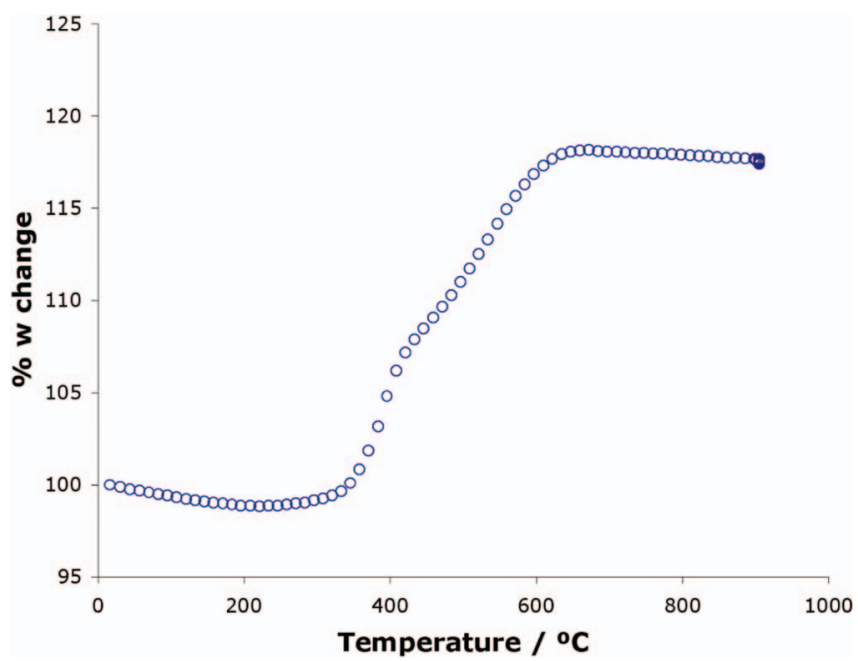

Figure 3. Weight gain of the nickel foam in air. This value is used to estimate the metal content in the foam.
Figure 5a shows the original scaffold of LST followed by an image of the infiltrated nickel in Figure 5b obtained by microwave decomposition of the nitrate/glycine solution. The micrograph of Figure $5 b$ showed circular areas of nickel in the inner walls of the pores that were the result of the bubbles generated during the evaporation of the water; in a way they are the bi-dimensional equivalent of the pores seen in the foam (Figure 1b). The nickel layer is well stuck to the surface of the pores, since the underlying structure of the pores is still visible. It is also clear that the nickel nitrate decomposition led to nickel metal layers attached to the walls of the pores rather than to foam. It is worth mentioning that pictures in Figure 5 were taken from the innermost part of the sample. Finally, Figure $5 \mathrm{c}$ shows a high magnification micrograph of the nickel attached to the LST scaffold. The coat had a thickness of 200-300 nm and consisted of an agglomeration of nanoparticles.

Figure $6 \mathrm{a}$ shows a clean fracture of a virgin scaffold of BCZYZ while Figure $6 \mathrm{~b}$ shows the fracture surface of the pores with a nickel deposit. The particular image presented corresponds to the innermost center of the bar used indicating that the nickel reached the interior

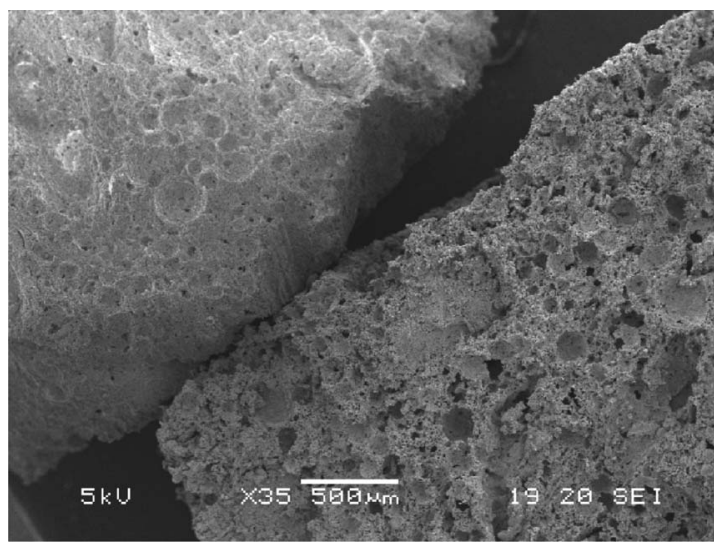

Figure 4. Clean Saffil cubes top left. Bottom right sample has been loaded 5 times up to $66 \mathrm{w} \%$ of nickel. Note the difference in intensity due to the better conductivity of the Ni impregnated sample. 


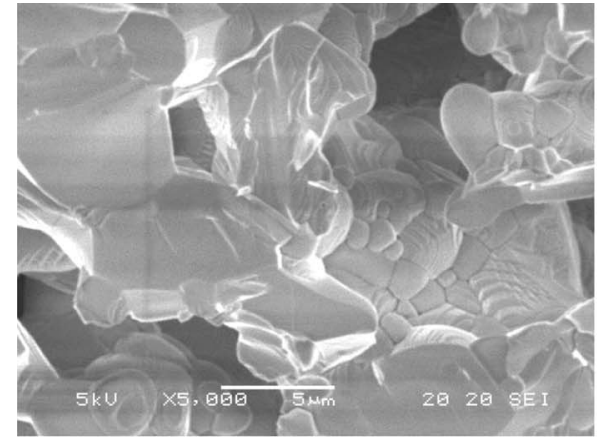

(a)

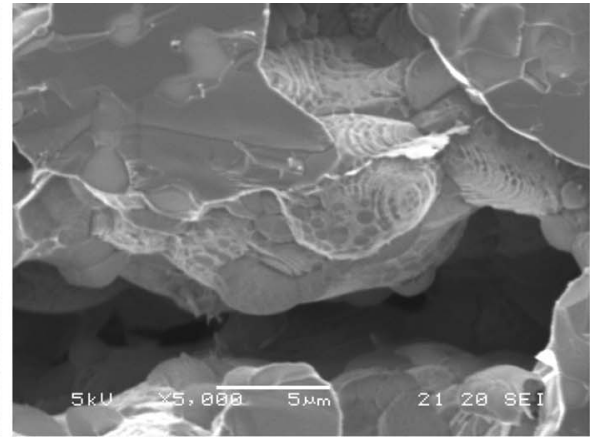

(b)

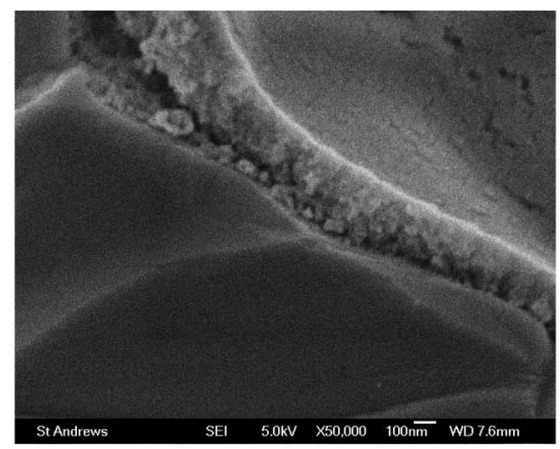

(c)

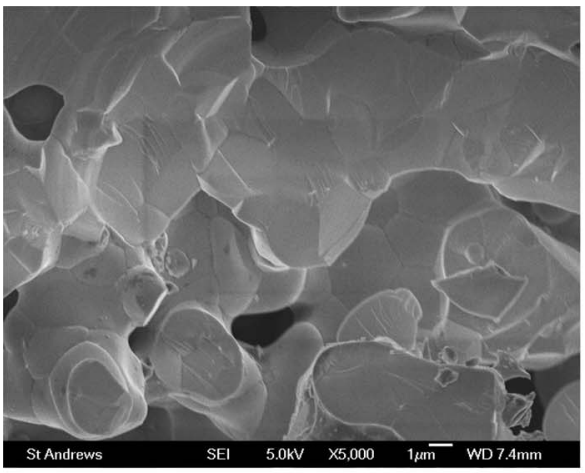

(a)

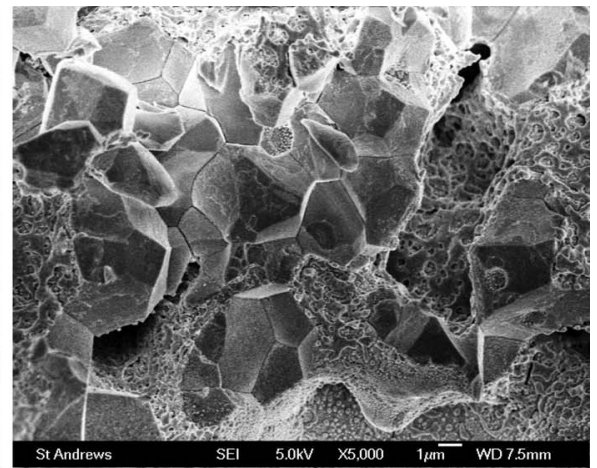

(b)

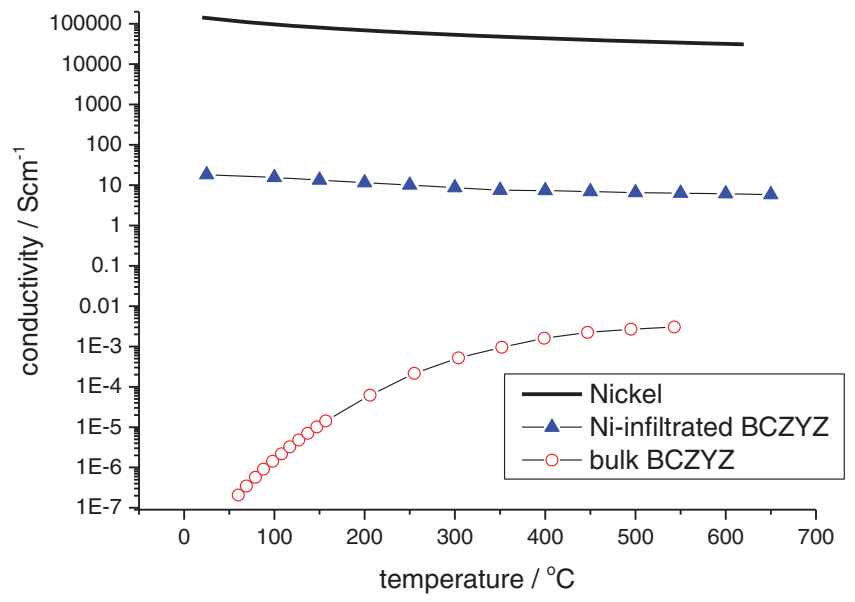

Figure 7. Conductivity of a BCZYZ sample with a $2 \%$ gain weight compared with pure nickel and nominally pure bulk BCZYZ conductivities [2].
Figure 5. a) Micrograph of a fracture surface of an LST scaffold. Some features are visible: some fresh clean fractures, the surface of the pores and the ripples in the scaffold. b) A fracture surface of a LST scaffold impregnated with Ni. Note the presence of cracks in the nickel layer and the visibility of the original LST ripples under the nickel layer. c) FESEM Micrograph of the LST backbone impregnated with nickel $2 \mathrm{w} \%$.
Figure 6. A) Clean fracture of a virgin scaffold of BCZYZ. B) Fracture surface with nickel. 


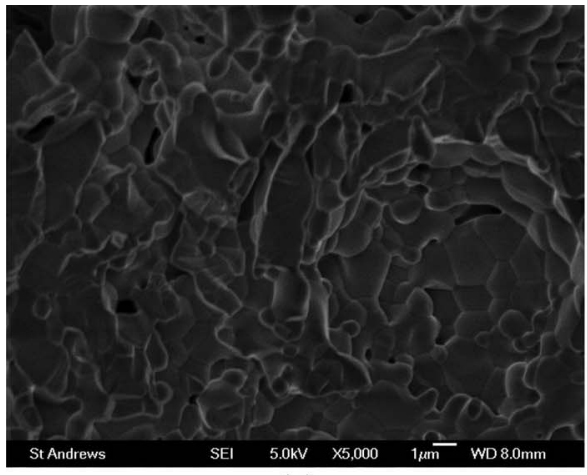

(a)

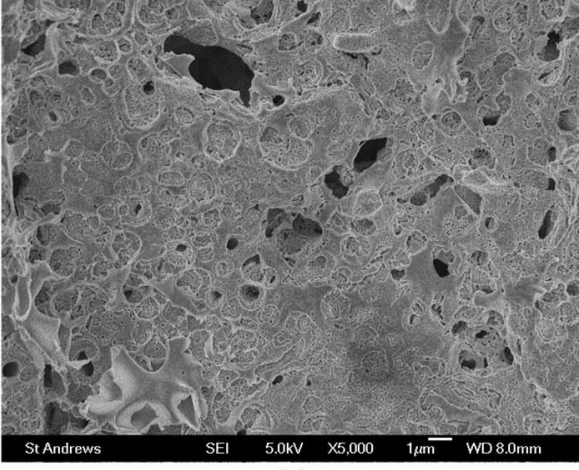

(b)

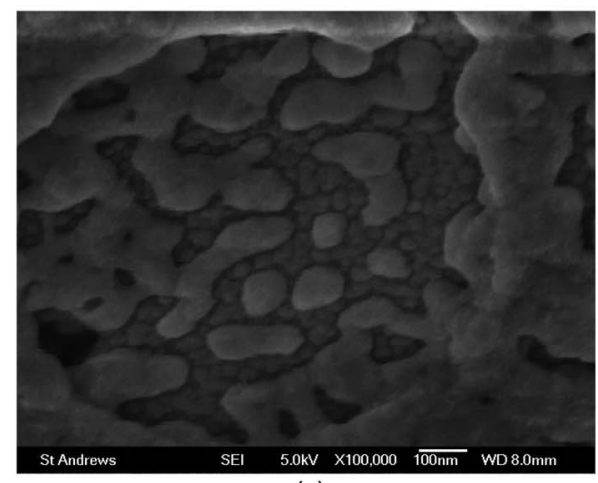

(c)

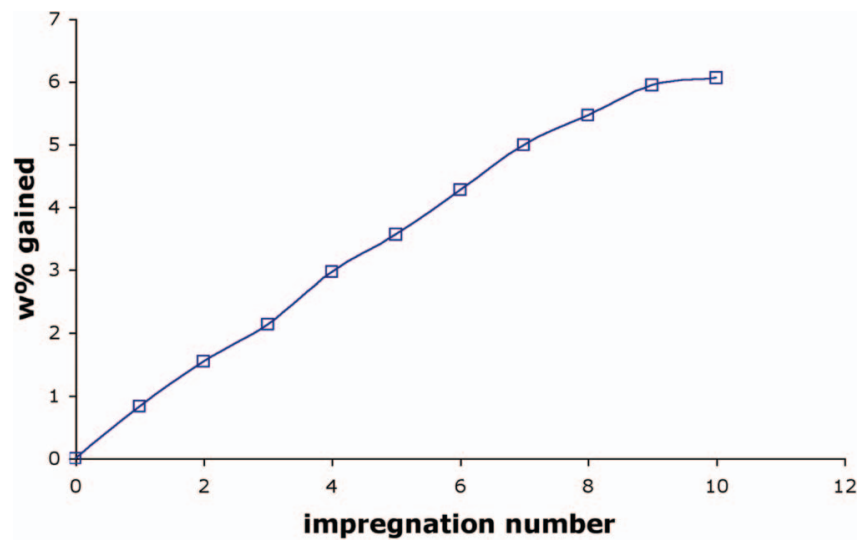

Figure 9. Weight gained after each impregnation. Saturation is reached after 10 cycles of impregnation and irradiation. The sample did not present any damage.

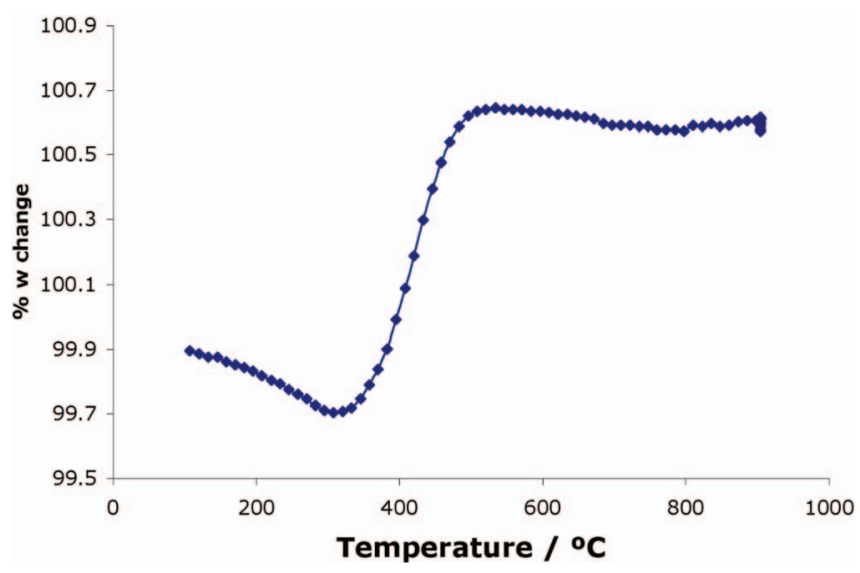

Figure 10. Weight gain of a CGO sample impregnated 10 times.
Figure 8. Micrograph of the CGO porous scaffold. a) Virgin scaffold. b) Interior of the sample after 10 impregnation-irradiation cycles. c) Nanostructure of the nickel formed inside the pores. gain, however, the value of ca. $1 \%$ matched our expectations. Another value that can be estimated is the vol\% occupied by the $\mathrm{Ni} / \mathrm{NiO}$. The initial open pore volume in the sample is $4 \times 10^{-4} \mathrm{~cm}^{3}$ while the volume of $\mathrm{Ni} / \mathrm{NiO}$ is $2 \times 10^{-4} \mathrm{~cm}^{3}$. It is then about $50 \%$ of the volume of the pores that can be easily filled with nickel. Notably, this quantity is enough to produce a percolating network of nickel necessary for a SOFC anode.

Figure 11a shows a cross section of the impregnated CGO sample and the area used to obtain an average EDX spectrum is indicated as well. The average spectra is shown in Figure $11 \mathrm{~b}$ while spectra taken at different points inside the indicated area revealed points where $\mathrm{Ni}$ was the main component and others where CGO prevailed, although a mixture of both appeared in most of the locations measured. This figure proves that a deep infiltration and microwave-assisted ignition of the nickel solution is possible. There are other factors affecting the infiltration of the solution, for example the wetting properties of the solution itself or the level of porosity of the matrix to be impregnated.

\section{Discussion}

Reaction and stoichiometry.- In principle, it is possible to write a full reaction that produces nickel without resorting to oxygen.

$$
3 \mathrm{Ni}\left(\mathrm{NO}_{3}\right)_{2}+4 \mathrm{NH}_{2}-\mathrm{CH}_{2}-\mathrm{COOH} \rightarrow 5 \mathrm{~N}_{2}+8 \mathrm{CO}_{2}+10 \mathrm{H}_{2} \mathrm{O}+3 \mathrm{Ni}
$$

It is however more likely that the reaction mechanism of combustion will be similar to that of ammonium nitrate leading to oxides of nitrogen $\left(\mathrm{NO}_{\mathrm{x}}\right)$ rather than molecular nitrogen at the high temperatures reached. ${ }^{13}$ Furthermore, the decomposition of nickel nitrate leads to $\mathrm{NiO}$ as well as to the formation of $\mathrm{NO}_{\mathrm{x}} \cdot{ }^{14}$ The presence of orange gases during combustion seems to support this decomposition mechanism.

Carbon monoxide is produced from the partial oxidation of carboncontaining compounds when not enough oxygen is available to produce carbon dioxide. This can happen if the combustion is fast enough to produce oxygen starvation at a local level. In conditions of glycine excess, two reactions can take place. One is the full oxidation of 


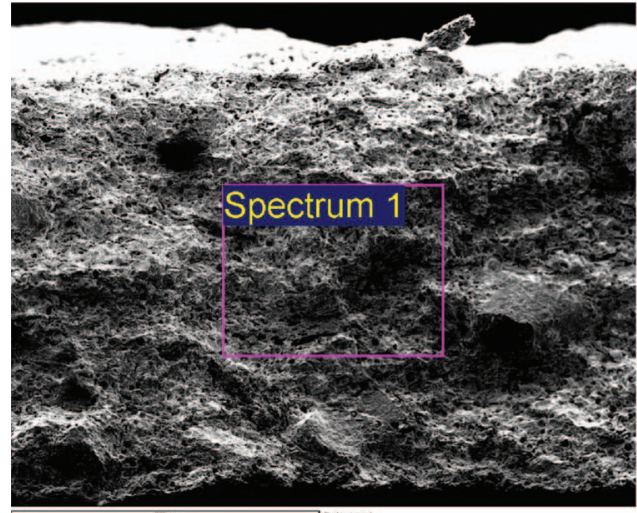

(a)

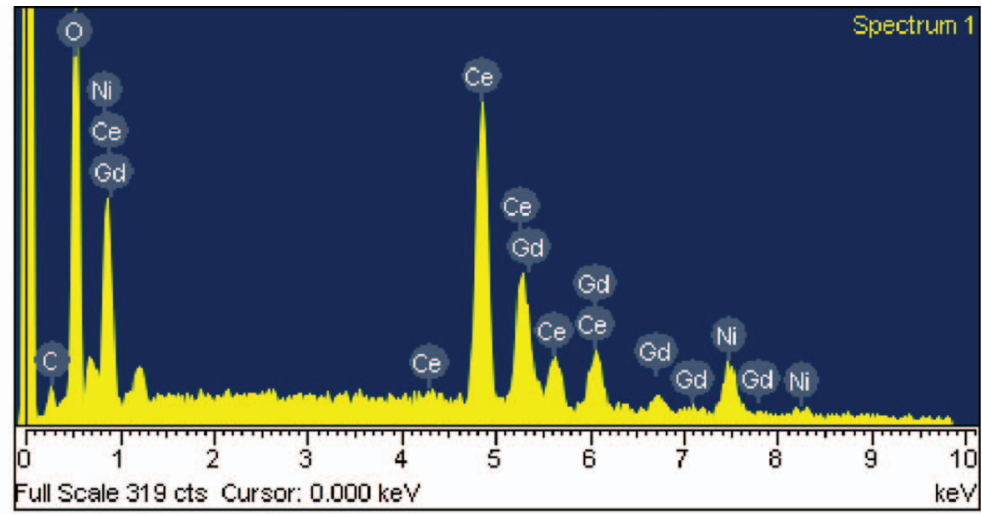

(b)

Figure 11. a) cross section of the impregnated CGO sample and the area used to obtain the average EDX spectrum shown in b).

glycine:

$$
4 \mathrm{NH}_{2}-\mathrm{CH}_{2}-\mathrm{COOH}+9 \mathrm{O}_{2} \rightarrow 8 \mathrm{CO}_{2}+10 \mathrm{H}_{2} \mathrm{O}+2 \mathrm{~N}_{2}
$$

and the other one is its partial oxidation:

$$
4 \mathrm{NH}_{2}-\mathrm{CH}_{2}-\mathrm{COOH}+5 \mathrm{O}_{2} \rightarrow 8 \mathrm{CO}+10 \mathrm{H}_{2} \mathrm{O}+2 \mathrm{~N}_{2}
$$

It is probably a combination of the last two reactions that actually takes place. A key point to the synthesis of metallic nickel is the reducing atmosphere produced by the local equilibrium between $\mathrm{CO}_{2}$ and $\mathrm{CO}$ according to:

$$
\mathrm{CO}+1 / 2 \mathrm{O}_{2} \rightarrow \mathrm{CO}_{2}
$$

This low partial pressure of oxygen can lead to the reduction of the metal oxide.

$$
\mathrm{NiO} \rightarrow \mathrm{Ni}+1 / 2 \mathrm{O}_{2}
$$

Other authors ${ }^{7}$ have suggested hydrogen coming from the glycine as the main reducing agent even though the pyrolysis of amino acids usually leads to $\mathrm{NH}_{3}, \mathrm{CO}_{2}$ and water. ${ }^{15}$

The ratio of glycine to nitrate ions is of great relevance as the lean fuel compositions do not ignite and other glycine rich stoichiometries do not provide the vigorous reaction to produce the metal phase.

The main difference between heating in a hot plate and in the microwave oven is the homogeneity and speed of the heating: the hot plate relies on convection for heating the transmission while the microwave heating is more homogeneous and fast. It is not known as yet if the microwaves catalyze the reaction of combustion.

Microstructure.-The evolution of gases during the reaction leaves nickel foam behind. A constant throughout Figures 1a-1c is the presence of round pores in all sizes: sub-millimetric, sub-micrometric and nanometric. The different sizes of pores are related to the different steps of the reaction: the larger sub-millimeter pores are formed when the solution boils. The sub-micrometric pores are probably formed during the evolution of the reaction gases while the less common nanometric pores seem to be more associated to nickel nanoparticles flaking off. The size of the pores and the distribution were not under control at this stage of the investigation but can certainly be modified for example by decreasing the irradiation to incorporate a slow de-hydrating step or by incorporating a surfactant to the solution to decrease the surface tension.

Another feature of the foam is observed in Figure 1c: the particles are welded together. This sintering may be due to the direct effect of the microwaves on the nanoparticles ${ }^{16}$ or favored during the high temperature achieved during the combustion. This feature may help forming a percolating network inside a porous scaffold.

Impregnation. - The incorporation of nickel metal into a porous structure is possible by microwave assisted-decomposition of a nitrate- glycine mixture. The nickel deposited attaches firmly to interior of the pores and repeated impregnations can be carried out. Tolerance to the expansion of gases and speed of metal loading depend upon the nature of the porosity and the mechanical stability of the scaffold. In all the samples shown here and up to the number of impregnated cycles presented no fracture or fissure was observed. Several questions arise here as to the mechanical stability of a scaffold during the gas and heat release. Saffil, the insulating material used in furnaces, a very soft material with large porosity did not suffer any damage upon repeated impregnation and irradiations; a high metal load with a small number of impregnations can be obtained rapidly. The impregnation of LST, CGO and BCZYZ shows that it is also possible to deposit nickel in the interior of the pores. The repeated impregnation and irradiation of small cubicles resulting in no damage shows that it is possible for the porous scaffold to stand such reaction. We believe that the impregnation of larger or thinner samples may be limited by the type of microwave oven used and not by the process itself as will be discussed below.

Undoubtedly, the fast impregnation of porous CGO and BCZYZ is very encouraging. The cycles lead to a constant and stable weight gain when a limit load was reached. The microstructure is also of great interest as the nickel is nanostructured, very well attached to the inner walls of the pores and as demonstrated in Figure 7 the nickel is percolating in BCZYZ even with only a $2 \mathrm{w} \%$ of $\mathrm{Ni} / \mathrm{NiO}$.

A major advantage of this process of nickel impregnation presented here is the time and energy saved. First, as opposed to the process of impregnation that involves repeated heating of the whole sample; the scaffold to be infiltrated is not heated as it is transparent to microwaves like most ceramics. Second, the reaction takes only $60 \mathrm{~s}$ as opposed to the times involved in the thermal cycles in a high temperature furnace.

Challenges and perspectives. - The experiments here documented were performed in a conventional microwave oven. This has severe limitations for the scaling of the reaction due to the original design and purpose of the oven. A conventional microwave oven has hot and cold spots, making it difficult to initiate reactions where very small amounts of liquid are involved. Ideally, it is necessary to concentrate the radiation in the region of interest rather than to map the hot-cold zones to place the sample in a hot spot; the mapping can be done but it is a rather cumbersome process.

The amounts of gases released represent another problem and so does the heat released when using large amounts of liquid (i.e. $>5 \mathrm{ml}$ ). First, the oven used does not have the capacity to extract the gases produced quickly and second, the flames produced during the combustion can turn into plasma induced by the microwaves. A larger oven with suitable gas extraction and size can solve these problems.

A critical and practical challenge is the violent reaction of combustion: if the scaffold to be used is very thin $(<0.5 \mathrm{~mm})$ it cracks. However, when the material is sufficiently porous no structural damage 
takes place as shown by the repeated impregnation of Saffil or when the scaffold has enough mechanical stability as in the case of CGO or BCZYZ. Only a small number of impregnating cycles was achieved with LST as the porosity did not allow a rapid evacuation of the reaction gases. A microwave oven that has no nodes or that can direct the microwaves in a specific spot can overcome these challenges. The energy used in the reaction can be used more efficiently if the microwaves are focused on the sample rather than in a large volume as in a conventional microwave oven.

In addition to its use as anode material, other applications of the nickel foam produced here can include: as electrode substrate in alkaline fuel cells ${ }^{17}$ or an alternative to nickel Raney. ${ }^{18}$

\section{Conclusions}

It is possible to prepare nickel metal from the microwave assisted combustion of glycine and the metal nitrate within $60 \mathrm{~s}$. The resulting material is a nickel foam with pores of different size ranging from the sub-millimetric to the nanometric. The method is reproducible and the metal yields average $80 \mathrm{w} \% \mathrm{Ni}$ and $20 \mathrm{w} \% \mathrm{NiO}$. The foam consists of welded nanoparticles with an average size of $45-47 \mathrm{~nm}$ and BET surface of $15.9 \mathrm{~m}^{2} \mathrm{~g}^{-1}$ and the oxide is probably coating the metal particles.

This synthesis has then been applied to accelerate the impregnation of porous scaffolds as a potential method to prepare electrodes for solid oxide fuels cells. Four different scaffolds Saffil, CGO, BCZYZ and LST were impregnated and irradiated repeatedly to load nickel metal. Our results indicate that, provided the scaffolds are mechanically stable, it is possible to impregnate the samples with nickel metal inside the porous backbone; the nickel attaches well to the walls of the pores, an even distribution can be achieved and metallic conductivity has been measured in $\mathrm{Ni} / \mathrm{BCZYZ}$. As opposed to a conventional impregnation method, a high yield of metal nickel is obtained without needing reduction with hydrogen. The nickel deposited shows a rich texture with grains below $50 \mathrm{~nm}$ in diameter. Repeated impregnation was possible for CGO, BCZYZ and Saffil and the porous scaffolds were not destroyed during the process. The next challenge is to escalate the process method.

\section{Acknowledgments}

We thank Sasol for financial support. Thanks to Thuy Muhl and Dr Cristian Savaniu for providing CGO and LST samples and to Dr Richard Clarke for useful discussions.

\section{References}

1. A. Atkinson, S. Barnett, R. J. Gorte, J. T. S. Irvine, A. J. Mcevoy, M. Mogensen, S. C. Singhal, and J. Vohs, Nat. Mater, 3(1), 17 (2004).

2. E. Ruiz-Trejo and J. T. S. Irvine, Solid State Ionics, 216, 36 (2012).

3. E. Ruiz-Trejo and J. T. S. Irvine, Solid State Ionics, 252, 157 (2013).

4. M. Kishimoto, M. Lomberg, E. Ruiz-Trejo, and N. P. Brandon, J. Power Sources, 266, 291 (2014)

5. M. Lomberg, E. Ruiz-Trejo, G. Offer, and N. P. Brandon, J. Electrochem. Soc., 161(9), F899 (2014).

6. P. Erri, J. Nader, and A. Varma, Adv. Mater., 20(7), 1243 (2008)

7. A. Kumar, E. E. Wolf, and A. S. Mukasyan, Aiche J, 57(8), 2207 (2011).

8. C. H. Jung, S. Jalota, and S. B. Bhaduri, Mater. Lett., 59(19-20), 2426 (2005).

9. H. Mohebbi, T. Ebadzadeh, and F. A. Hesari, Powder Technol., 188(3), 183 (2009)

10. C. Parada and E. Moran, Chem. Mater, 18(11), 2719 (2006).

11. J. Rodríguez-Carvajal, Phys. B, 192(1-2), 55 (1993).

12. R. D. Shull, R. D. McMichael, L. J. Swartzendruber, and S. D. Leigh, J. Appl. Phys., 87(9), 5992 (2000)

13. T. B. Brill, P. J. Brush, and D. G. Patil, Combust Flame, 92(1-2), 178 (1993).

14. A. M. Gadalla and H. F. Yu, Thermochim. Acta, 164, 21 (1990).

15. P. G. Simmonds, G. P. Shulman, M. A. Ratcliff, and E. E. Medley, Anal. Chem., 44(12), 2060 (1972).

16. D. Demirskyi, D. Agrawal, and A. Ragulya, J. Alloys Compd, 509(5), 1790 (2011).

17. F. Bidault, D. J. L. Brett, P. H. Middleton, N. Abson, and N. P. Brandon, Int. J. Hydrogen Energy, 34(16), 6799 (2009).

18. M. Raney. US patent $1,563,787$ (1925). 